\title{
Technical challenges in totally endoscopic robotic coronary artery bypass grafting
}

\author{
J. Bonatti, MD, FETCS, ${ }^{a}$ T. Schachner, MD, ${ }^{a}$ N. Bonaros, MD, ${ }^{a}$ A. Öhlinger, MD, ${ }^{a}$ M. Danzmayr, ${ }^{a}$ \\ P. Jonetzko, MD, ${ }^{c}$ G. Friedrich, MD, ${ }^{c}$ C. Kolbitsch, MD, DEAA, ${ }^{b}$ P. Mair, MD, and G. Laufer, MD, ${ }^{a}$
}

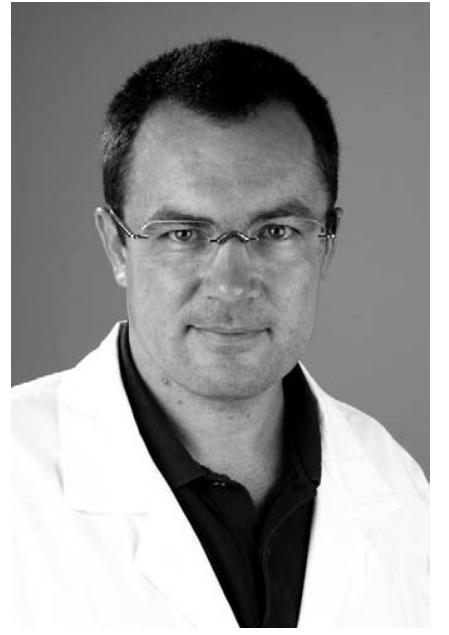

Dr Bonatti

From the Departments of ${ }^{\mathrm{a} C a r d i a c}$ Surgery, ${ }^{\mathrm{b}}$ Cardiac Anesthesia and, ${ }^{\mathrm{c}}$ Cardiology, Innsbruck Medical University, Innsbruck, Austria.

Received for publication Feb 13, 2005; revisions received July 3 , 2005; accepted for publication July 19, 2005

Address for reprints: Johannes Bonatti, MD, Associate Professor of Surgery, Innsbruck Medical University, Department of Cardiac Surgery, Anichstrasse 35, A-6020 Innsbruck, Austria (E-mail: johannes.o. bonatti@uibk.ac.at).

J Thorac Cardiovasc Surg 2006;131:146-53 $0022-5223 / \$ 32.00$

Copyright (C) 2006 by The American Association for Thoracic Surgery

doi:10.1016/j.jtcvs.2005.07.064
Objective: Robotic technology is a prerequisite for performance of totally endoscopic coronary artery bypass grafting. During the implementation phase of totally endoscopic coronary artery bypass, surgeon-related technical difficulties might be encountered. It was the aim of this study to assess the incidence of these challenges, to find risk factors, and to describe clinical results associated with technical errors.

Methods: From October 2001 through October 2004, 40 patients received robotically assisted totally endoscopic left internal thoracic artery grafts to the left anterior descending coronary artery system with the da Vinci telemanipulation device. All patients underwent remote access cardiopulmonary bypass perfusion through groin access, and all anastomoses were performed on the arrested heart.

Results: Undesirable technical events of various grades occurred in 20 (50\%) of 40 patients: bleeding from a port hole in $3(8 \%)$, left internal thoracic artery damage in $3(8 \%)$, epicardial lesion in $3(8 \%)$, remote access perfusion problems in $9(23 \%)$, bleeding from the anastomosis in $4(10 \%)$, and anastomotic stenosis in $2(5 \%)$. There was no hospital mortality. The following differences were noted between patients without technical difficulties (group 1) and those in whom problems occurred (group 2): total operative time of 314 minutes (260-540 minutes) versus 418 minutes (270-690 minutes; $P=.007)$, ventilation time of 6 hours $(0-26$ hours) versus 14 hours ( 0 -278 hours; $P=.004)$, intensive care unit stay of 20 hours (11-70 hours) versus 44 hours (16-336 hours; $P=.183$ ), hospital stay of 7 days (4-13 days) versus 8 days (5-21 days; $P=.038)$, and cumulative freedom from angina at 36 months of $93 \%$ versus $100 \%(P=.317)$.

Conclusion: We conclude that technical difficulties during totally endoscopic coronary artery bypass grafting translate into markedly increased operative time, moderately prolonged postoperative ventilation time, and slightly increased hospital stay. Short-term survival and freedom from angina, however, do not seem to be compromised.

I $\mathrm{n}$ the mid-1990s, several initial attempts to perform endoscopic coronary artery bypass grafting (CABG) with conventional thoracoscopic instrumentation failed. The following introduction of surgical telemanipulation systems enabled more complex intrathoracic maneuvers, and Loulmet and colleagues ${ }^{1}$ carried out the first totally endoscopic coronary artery bypass (TECAB) procedure in 1998. Despite this successful step, only a limited number of TECAB operations have thus far been carried out worldwide. The high cost of the equipment and procedure time issues are the main arguments against robotic endoscopic CABG. Another reason for poor acceptance might also be the fact that this operation remains a technically difficult surgical challenge. ${ }^{2,3}$ Thus far, little has been reported about specific technical obstacles that might be encountered during the TECAB procedure. Given the fact that several surgical teams are planning or currently installing a robotic cardiac 


\section{Abbreviations and Acronyms \\ $\mathrm{AHTECAB}=$ arrested heart totally endoscopic coronary artery bypass \\ $\mathrm{CABG}=$ coronary artery bypass grafting \\ ITA $=$ internal thoracic artery \\ LITA $\quad=$ left internal thoracic artery \\ $\mathrm{TECAB}=$ totally endoscopic coronary artery bypass}

TABLE 1. Definition of problem severity levels in AHTECAB

Level $0 \quad$ No problems

Level 1 Intraoperative events that cause significant delay during conduct of the procedure ( $\geq 15 \mathrm{~min}$ )

Level 2 Events that force the surgeon to change his or her operative strategy immediately by conversion to a larger incision before finishing the endoscopic procedure (minithoracotomy or sternotomy)

Level 3 Problems that necessitate surgical revisions on the operating table through a larger incision (minithoracotomy or sternotomy) after completion of the endoscopic procedure but during the same operative session (eg, after pathologic findings on intraoperative angiography)

Level 4 Problems that necessitate surgical revisions through a larger incision during the immediate postoperative period (first $24 \mathrm{~h}$ )

Level $5 \quad$ Major surgical problem leading to significant and immediate therapeutic measures, including cardiopulmonary resuscitation, significant inotropic support, placement of ECMO or other mechanical assist devices, massive blood transfusion, or situations requiring a major additional surgical intervention at any time in the intraoperative or postoperative course (eg, significant low cardiac output, aortic dissection, bleeding from large vessels, bleeding from the left or right ventricle, massive pulmonary laceration)

AHTECAB, Arrested heart totally endoscopic coronary artery bypass; $E C M O$, extracorporeal membrane oxygenation.

Anesthesia. After induction of anesthesia, a left-sided, doublelumen endobronchial tube was placed. Anesthesia was maintained with remifentanil $\left(0.2-0.5 \mu \mathrm{g} \cdot \mathrm{kg}^{-1} \cdot \mathrm{min}^{-1}\right)$ and propofol or sevoflurane. A central venous line, a Swan-Ganz catheter, and percutaneous defibrillator patches were placed. Bilateral radial arterial pressure lines and transesophageal echocardiography completed monitoring.

Surgical procedure. The patient was positioned in a $30^{\circ}$ right lateral decubitus position. After setup of the da Vinci system (Intuitive Surgical, Sunnyvale, Calif) a camera port was introduced into the left fifth intercostal space on the anterior axillary line under left lung collapse. $\mathrm{CO}_{2}$ was insufflated at target pressures of $10 \mathrm{~mm} \mathrm{Hg}$. Instrument ports were then inserted through the third and seventh intercostal spaces on the mamillary line under thoracoscopic vision. The internal thoracic artery (ITA) was localized, and the endothoracic fascia and transverse thoracic muscle were removed from the ITA pedicle to adequately visualize the vessel. By using electrocautery at $20 \mathrm{~W}$ and endoscopic clips for division of pedicle side branches, the ITA was harvested from the first onto the fifth intercostal space. Heparin (300 IE/kg) was administered, and after endoscopic placement of a temporarily occluding bulldog clamp, preparation of the distal graft portion, as well as free flow check, were carried out.

The pericardial fat pad was removed from the pericardium by using electrocautery. After incision of the pericardium, the left anterior descending coronary artery was identified and marked with a clip onto the adjacent epicardial fat. Care was taken to see the left anterior descending coronary artery running around the apex of the heart to avoid confusion with diagonal branches.

In parallel to these steps, the femoral artery and femoral vein were exposed in the left groin. The right atrium was cannulated for cardiopulmonary bypass with a $25 \mathrm{~F}$ or $27 \mathrm{~F}$ Medtronic venous return cannula (96370; Medtronic, Minneapolis, Minn). A 21F Remote Access Perfusion cardiopulmonary bypass system (ESTECH, Danville, Calif) or a 21F Endoreturn (Heartport, Redwood City, Calif) arterial cannula was inserted, cardiopulmonary bypass was started, and the ascending aortic occlusion balloon was inflated for induction of cardioplegia.

Thereafter, the target vessel was exposed and incised with a lancet endoscopic knife. The left ITA (LITA) was then sutured robotically to the target vessel with a 7-0 Pronova (PN 8713; Johnson and Johnson, Somerville, NJ) running suture. The sternal and heel parts of the anastomosis were sutured first and carried out in an outside-in manner, and thereafter, the toe of the anastomosis and the lateral portion were carried out in an inside-out manner.

After deflating the endoaortic occlusion balloon, the heart was reperfused and defibrillated percutaneously if necessary. After rewarming and reperfusion, the patient was weaned from cardio- 
TABLE 2. Incidence and type of technical difficulties in AHTECAB $(n=40)$

\begin{tabular}{lrr}
\hline & No. & $\%$ \\
\hline Patients with technical difficulty & 20 & 50 \\
Conversion (intraoperative) & 6 & 15 \\
On-table revision & 3 & 8 \\
Postoperative revision procedure & 4 & 10 \\
Additional larger incision & & \\
$\quad$ Sternotomy & 11 & 28 \\
$\quad$ Minithoracotomy & 2 & 5 \\
LITA injury & 1 & \\
$\quad$ LITA bleeding & 3 & 3 \\
$\quad$ LITA intramural hematoma & 3 & 8 \\
Epicardial lesion & & \\
Anastomotic problem & 1 & 3 \\
$\quad$ Wrong target vessel & 4 & 10 \\
$\quad$ Anastomotic bleeding & 2 & 5 \\
$\quad$ Anastomotic stenosis & 9 & 8 \\
Remote access perfusion problem & 3 & \\
Port problem (bleeding) & &
\end{tabular}

Multiple events were experienced in 7 patients. AHTECAB, Arrested heart totally endoscopic coronary artery bypass; LITA, left internal thoracic artery.

pulmonary bypass and decannulated. Intraoperative graft angiography was a routine measure of quality control in all cases.

Undesirable surgical events occurred in 20 (50\%) of our patients. Patients without technical problems were assigned to group 1 , and patients with technical problems were assigned to group 2 .

Definition and Grading of Technical Difficulties Technical difficulties were graded as shown in Table 1.
Definition of Conversions and On-table or

\section{Postoperative Revision Procedures}

A "conversion" was defined as an event that mandated a switch to a larger thoracic incision (minithoracotomy or sternotomy) during conduct of the AHTECAB procedure. An "on-table revision" was defined as a repair operation through a larger incision that was carried out during the same operative session after completion of the AHTECAB operation. A "postoperative revision procedure" was a repair operation that had to be carried out after transfer of the patient to the intensive care unit.

\section{Statistics}

The statistical computer package SPSS 11.0.0 for Windows (SPSS, Chicago, Ill) was used for statistical analysis. Categoric variables are presented as percentages and absolute values, and continuous variables are presented as medians and ranges. Intergroup comparisons were performed by using the $\chi^{2}$ test for categoric variables and the Mann-Whitney $U$ test for continuous variables. Life-table analysis was taken for calculation of freedom from angina. In the figures mean severity level of technical difficulties is presented as the mean \pm standard deviation.

\section{Results}

Table 2 lists the specific surgical difficulties that occurred in this series, and mean severity levels are shown in Figure 1. Intraoperative conversions to sternotomy or minithoracotomy were required in $6(15 \%)$ of the 40 patients. Table 3 depicts specific technical difficulties and the corresponding severity level in patients 1 through 40. LITA damage and bleeding occurred early in the TECAB series, whereas port bleeding occurred as a cluster in the middle third of the experience. Remote access perfusion problems were encountered throughout the whole series but with an acceptable severity level, except for one external iliac artery perforation caused
Figure 1. Severity level of different surgical problems during totally endoscopic coronary artery bypass grafting on the arrested heart. Levels are depicted as means \pm standard deviation. LITA, Left internal thoracic artery.

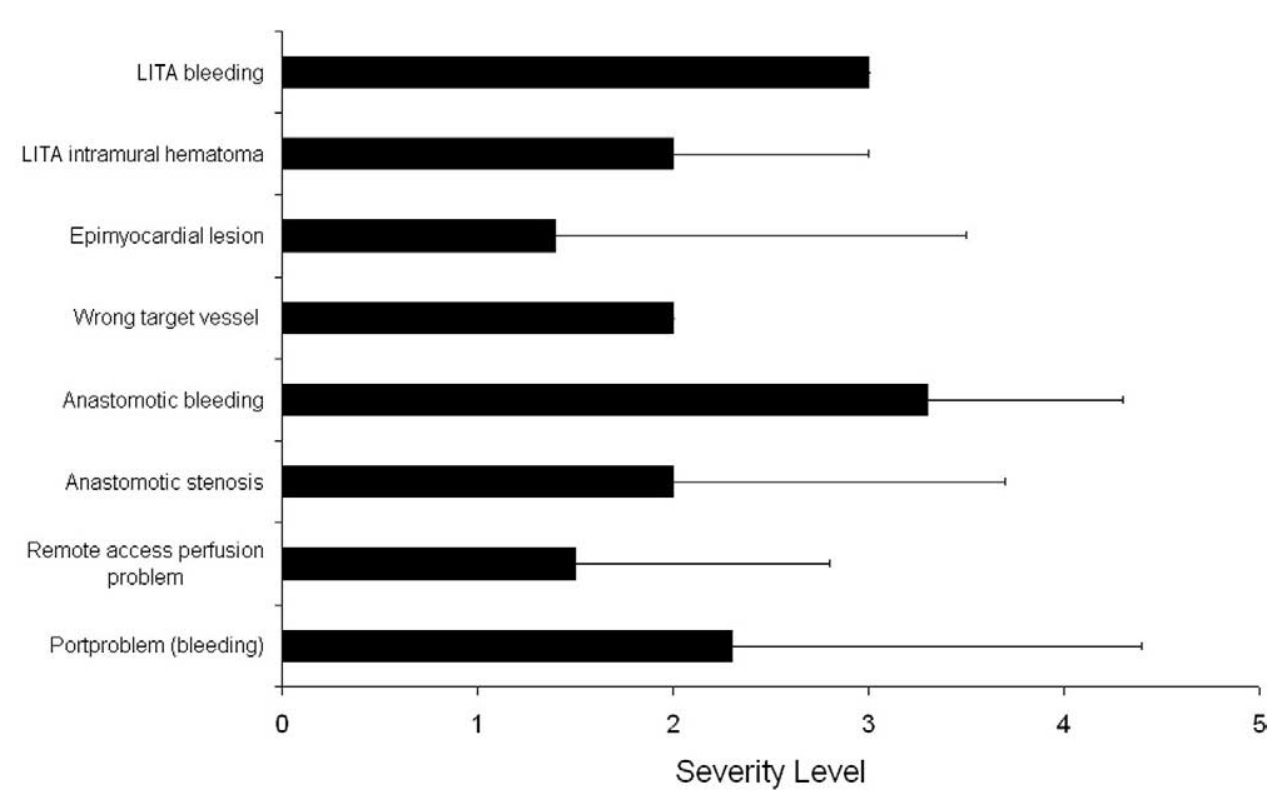


TABLE 3. Severity level of technical difficulties (overall and for specific difficulties) in AHTECAB

\begin{tabular}{|c|c|c|c|c|c|c|c|c|c|}
\hline No. & Overall & $\begin{array}{c}\text { LITA } \\
\text { damage }\end{array}$ & $\begin{array}{c}\text { LITA } \\
\text { bleeding }\end{array}$ & $\begin{array}{l}\text { Epicardial } \\
\text { lesion }\end{array}$ & $\begin{array}{c}\text { Wrong target } \\
\text { vessel }\end{array}$ & $\begin{array}{l}\text { Anastomotic } \\
\text { bleeding }\end{array}$ & $\begin{array}{l}\text { Anastomotic } \\
\text { stenosis }\end{array}$ & $\begin{array}{c}\text { Remote access } \\
\text { perfusion problem }\end{array}$ & $\begin{array}{c}\text { Port } \\
\text { problem }\end{array}$ \\
\hline 1 & 0 & & & & & & & & \\
\hline 2 & 2 & & & & & 2 & & & \\
\hline 3 & 2 & & & & 2 & & & 2 & \\
\hline 4 & 0 & & & & & & & & \\
\hline 5 & 1 & & & & & & & 1 & \\
\hline 6 & 2 & 2 & & & & & & & \\
\hline 7 & 0 & & & & & & & & \\
\hline 8 & 3 & & & & & 3 & 3 & & \\
\hline 9 & 0 & & & & & & & & \\
\hline 10 & 0 & & & & & & & & \\
\hline 11 & 1 & & & & & & 1 & & \\
\hline 12 & 0 & & & & & & & & \\
\hline 13 & 3 & 3 & 3 & & & & & & \\
\hline 14 & 0 & & & & & & & & \\
\hline 15 & 1 & & & & & & & 1 & \\
\hline 16 & 0 & & & & & & & & \\
\hline 17 & 0 & & & & & & & & \\
\hline 18 & 0 & & & & & & & & \\
\hline 19 & 4 & & & & & & & & 4 \\
\hline 20 & 3 & & & & & & 3 & & \\
\hline 21 & 1 & & & 1 & & & & & \\
\hline 22 & 0 & & & & & & & & \\
\hline 23 & 0 & & & & & & & & \\
\hline 24 & 2 & & & & & & & 2 & 1 \\
\hline 25 & 4 & 1 & & & & & & & 4 \\
\hline 26 & 4 & & & & & 4 & & 1 & \\
\hline 27 & 0 & & & & & & & & \\
\hline 28 & 1 & & & & & & & 1 & \\
\hline 29 & 0 & & & & & & & & \\
\hline 30 & 0 & & & & & & & & \\
\hline 31 & 0 & & & & & & & & \\
\hline 32 & 4 & & & & & 4 & & 1 & \\
\hline 33 & 0 & & & & & & & & \\
\hline 34 & 1 & & & 1 & & & & & \\
\hline 35 & 1 & & & & & & & 1 & \\
\hline 36 & 5 & & & & & & & 5 & \\
\hline 37 & 0 & & & & & & & & \\
\hline 38 & 5 & & & 5 & & & & & \\
\hline 39 & 0 & & & & & & & & \\
\hline 40 & 0 & & & & & & & & \\
\hline
\end{tabular}

AHTECAB, Arrested heart totally endoscopic coronary artery bypass; LITA, left internal thoracic artery.

by an additional perfusion cannula in the groin contralateral to the Remote Access Perfusion cannula. This event caused a large retroperitoneal hematoma. The patient required a prolonged intensive care unit stay with additional septic problems but was discharged without sequelae. There were 3 epimyocardial lesions. Two of them led to delay of the procedure, and in one of them an open suture was carried out through a sternotomy. Anastomotic stenoses $(\mathrm{n}=2)$ were detected by means of intraoperative angiography on the operating table and were repaired immediately. Anas- tomotic stenoses did not occur after the first half of the series. Two cases of anastomotic bleeding happened early, and 2 happened after an experience of more than 25 cases. These 4 cases resulted in significant surgical consequences corresponding to high severity levels of technical difficulties.

Demographic differences between groups 1 and 2 are shown in Table 4. No single demographic risk factor could be attributed to the occurrence of technical difficulties. Surgical problems translated into a significantly prolonged 
TABLE 4. Baseline characteristics of patients without (group 1) and with (group 2) technical difficulties in AHTECAB

\begin{tabular}{|c|c|c|c|}
\hline & $\begin{array}{l}\text { Group } 1 \\
(\mathrm{n}=20)\end{array}$ & $\begin{array}{l}\text { Group } 2 \\
(\mathrm{n}=20)\end{array}$ & $P$ value \\
\hline EuroSCORE & $1(0-3)$ & $1(0-4)$ & .678 \\
\hline Age (y) & $59(52-68)$ & $59(42-70)$ & .659 \\
\hline Male sex & $13(65 \%)$ & $15(75 \%)$ & \\
\hline Female sex & $7(35 \%)$ & $5(25 \%)$ & .490 \\
\hline Height (cm) & $172(158-184)$ & 172 (156-185) & .835 \\
\hline Weight (kg) & $79(48-107)$ & $72(52-100)$ & .214 \\
\hline $\mathrm{BMI}$ & $27(19-32)$ & $26(20-31)$ & .314 \\
\hline Hypertension & $17(85 \%)$ & $18(90 \%)$ & .633 \\
\hline Hypercholesterolemia & $10(55 \%)$ & $15(75 \%)$ & 1.102 \\
\hline Hypertriglyceridemia & $0(0 \%)$ & $3(15 \%)$ & .072 \\
\hline Diabetes & $2(10 \%)$ & $2(10 \%)$ & 1.000 \\
\hline Smoking & $7(35 \%)$ & $10(50 \%)$ & .337 \\
\hline Prior PTCA-stent & $7(35 \%)$ & $9(45 \%)$ & .519 \\
\hline Prior MI & $7(35 \%)$ & $9(45 \%)$ & .519 \\
\hline $\operatorname{LVEF}(\%)$ & $60(40-79)$ & $60(40-80)$ & .984 \\
\hline CVD & $0(0 \%)$ & $1(5 \%)$ & .311 \\
\hline PVD & $0(0 \%)$ & $0(0 \%)$ & 1.000 \\
\hline Chronic renal failure & $0(0 \%)$ & $0(0 \%)$ & 1.000 \\
\hline $\begin{array}{l}\text { Preoperative creatinine } \\
\text { (mg/dL) }\end{array}$ & $1.1(0.6-1.5)$ & $1.0(0.8-1.2)$ & .478 \\
\hline COPD & $3(15 \%)$ & $2(10 \%)$ & .633 \\
\hline
\end{tabular}

AHTECAB, Arrested heart totally endoscopic coronary artery bypass; $B M I$, body mass index; PTCA, percutaneous transluminal coronary angioplasty; $M I$, myocardial infarction; $L V E F$, left ventricular ejection fraction; $C V D$, cerebrovascular disease; $P V D$, peripheral vascular disease; COPD, chronic obstructive pulmonary disease.

total operative time of 418 minutes (270-690 minutes) versus 314 minutes (260-540 minutes; $P=.007$; Table 5). Operative time included intraoperative angiographic quality control and the time necessary to repair problems on the operating table.

As can be seen in Table 6, there was a significantly

TABLE 5. Intraoperative results in patients without (group 1) and with (group 2) technical difficulties in AHTECAB

\begin{tabular}{lccc}
\hline & $\begin{array}{c}\text { Group 1 } \\
(\mathbf{n}=\mathbf{2 0})\end{array}$ & $\begin{array}{c}\text { Group 2 } \\
(\mathbf{n = 2 0 )}\end{array}$ & $\boldsymbol{P}$ value \\
\hline LITA takedown time (min) & $48(35-85)$ & $55(35-70)$ & .314 \\
$\begin{array}{l}\text { Aortic endo-occlusion } \\
\quad \text { time (min) }\end{array}$ & $80(44-132)$ & $71(37-223)$ & .857 \\
$\begin{array}{l}\text { Anastomotic time (min) } \\
\text { CPB time (min) }\end{array}$ & $35(26-66)$ & $35(23-60)$ & .940 \\
$\begin{array}{l}\text { Total operative time* } \\
\quad \text { (min) }\end{array}$ & $3113(72-230)$ & $134(79-368)$ & .336 \\
& & & .007 \\
\end{tabular}

AHTECAB, Arrested heart totally endoscopic coronary artery bypass; LITA, left internal thoracic artery; $C P B$, cardiopulmonary bypass. *Including intraoperative angiography for quality control and on-table revision procedures. higher rate of postoperative surgical revisions for bleeding in group 2 and an increased amount of fresh frozen plasma administered intraoperatively. Postoperative ventilation time and hospital length of stay were significantly increased after the occurrence of difficulties during the conduct of the operation. For intensive care unit length of stay, there was a trend toward prolongation by surgical problems. There was no mortality in either group.

Cumulative freedom from angina at 3 years was $100 \%$ in group 1 and $93 \%$ in group 2 . One patient in this group

TABLE 6. Postoperative results in patients without (group 1) and with (group 2) technical difficulties in AHTECAB

\begin{tabular}{|c|c|c|c|}
\hline & $\begin{array}{l}\text { Group } 1 \\
(n=20)\end{array}$ & $\begin{array}{l}\text { Group } 2 \\
(n=20)\end{array}$ & $P$ value \\
\hline $\begin{array}{l}\text { Revision for bleeding } \\
\text { (after ICU admission) }\end{array}$ & $1(5 \%)$ & $6(30 \%)$ & .037 \\
\hline \multicolumn{4}{|l|}{ Median number of: } \\
\hline PRBC intraoperative & $0(0-4)$ & $1(0-19)$ & .102 \\
\hline PRBC ICU & $0(0-2)$ & $0(0-6)$ & .383 \\
\hline FFP intraoperative & $0(0-5)$ & $5(0-25)$ & .001 \\
\hline FFP ICU & $0(0-5)$ & $0(0-10)$ & .718 \\
\hline Inotropic support ICU & $2(10 \%)$ & $4(20 \%)$ & .661 \\
\hline IABP & $0(0 \%)$ & $1(5 \%)$ & .311 \\
\hline CK (U/L) & $984(71-6280)$ & $650(198-7672)$ & .916 \\
\hline CK-MB (U/L) & $25(7-137)$ & $25(13-78)$ & .816 \\
\hline Atrial fibrillation & $2(10 \%)$ & $3(15 \%)$ & .633 \\
\hline Ventilation time (h) & $6(0-26)$ & $14(0-278)$ & .004 \\
\hline Tracheostomy & $0(0 \%)$ & $1(5 \%)$ & .311 \\
\hline Pneumonia & $1(5 \%)$ & $1(5 \%)$ & 1.000 \\
\hline Hemofiltration & $0(0 \%)$ & $0(0 \%)$ & 1.000 \\
\hline Forced diuresis & $0(0 \%)$ & $3(15 \%)$ & .072 \\
\hline TIA & $0(0 \%)$ & $0(0 \%)$ & 1.000 \\
\hline Stroke & $0(0 \%)$ & $0(0 \%)$ & 1.000 \\
\hline MSOF & $0(0 \%)$ & $0(0 \%)$ & 1.000 \\
\hline Sepsis & $0(0 \%)$ & $1(5 \%)$ & .311 \\
\hline Mortality & $0(0 \%)$ & $0(0 \%)$ & 1.000 \\
\hline ICU stay (h) & $20(11-70)$ & $44(16-336)$ & .183 \\
\hline Hospital stay $(d)$ & $7(4-13)$ & $8(5-21)$ & .038 \\
\hline Cumulative survival & $100 \%$ & $100 \%$ & 1.000 \\
\hline $\begin{array}{l}\text { Cumulative } 3 \text { y freedom } \\
\text { from angina }\end{array}$ & $93 \%$ & $100 \%$ & .317 \\
\hline $\begin{array}{l}\text { Consent for 3-mo FU } \\
\text { angiogram }\end{array}$ & $13 / 20(65 \%)$ & $11 / 20(55 \%)$ & .519 \\
\hline \multicolumn{4}{|l|}{ 3-mo graft patency } \\
\hline Anastomosis & $13 / 13(100 \%)$ & $11 / 11(100 \%)$ & 1.000 \\
\hline $\begin{array}{l}\text { Distal target vessel (toe } \\
\text { of the anastomosis) }\end{array}$ & $13 / 13(100 \%)$ & $11 / 11(100 \%)$ & 1.000 \\
\hline $\begin{array}{l}\text { Proximal target vessel } \\
\text { (heel of the } \\
\text { anastomosis) }\end{array}$ & $13 / 13(100 \%)$ & $10 / 11(91 \%)$ & .267 \\
\hline
\end{tabular}

$\overline{A H T E C A B}$, Arrested heart totally endoscopic coronary artery bypass; ICU, intensive care unit; $P R B C$, packed red blood cells; FFP, fresh frozen plasma; $I A B P$, intra-aortic balloon pump; $C K$, creatine kinase; $C K-M B$, creatine kinase MB fraction; TIA, transitory ischemic attack; MSOF, multisystem organ failure; $F U$, follow-up. 
experienced a myocardial infarction 8 months postoperatively, and the culprit lesion was a right coronary artery lesion that was not present at the time of TECAB. There was no target vessel reintervention on the robotically sutured LITA grafts in the whole study group.

\section{Discussion}

The present study demonstrates that the implementation of TECAB on the arrested heart by using telemanipulation and remote access perfusion might be accompanied by a significant rate of surgical hurdles. The clinical consequences of these difficulties, however, seem to be acceptable. Technical difficulties that we encountered during TECAB development are in range with the experience reported by other groups. ${ }^{3,4}$

Detailed reports on the frequency of technical difficulties in cardiac surgery procedures and their severity levels and management strategies are rare in the literature. Technical difficulties are also rarely included in risk factor analyses of different procedures in cardiac surgery. A potential reason for this fact might be that except for notes in the operative report, technical errors are not recorded in standard cardiac surgery databases. For a new and complex totally endoscopic operation, such as AHTECAB, a detailed analysis of undesirable surgical events should help to improve the quality of the procedure and should be a useful tool for teaching this operation. When looking at the results of our analysis, it should be clearly remembered that an implementation phase with a variety of learning curves is described. ${ }^{5,6}$

A technical difficulty in our series was very broadly defined, and the event rate in half of our patients might seem high. It can be stated, however, that all difficulties were under control of the surgical team and that all problems could be corrected at least during the first postoperative hours. In addition, the overall severity level was low, and trends toward improvement were noted for some types of difficulties with increasing experience. Our conversion rate of $15 \%$ was comparable with that of others in the field of robotic totally endoscopic CABG. ${ }^{3,4}$ It was our group's strategy to generously perform sternotomies in view of technical difficulties because we think that this approach offers the best overview and enables a broad surgical reaction spectrum. Including postoperative revisions, $33 \%$ of our patients ended up with a larger incision, either minithoracotomy or sternotomy. This makes AHTECAB probably a difficult offer for the patient, and intense technological, as well as procedure-related, development will be necessary to increase the rate of procedures that can be achieved in a completely endoscopic fashion. Despite the high rate of revisions, which was already obvious at the beginning of our program, no patient refused the AHTECAB procedure because of this fact, and we are continuing to perform this operation. Ideally, prospective randomized trials will show whether robotic totally endoscopic procedures can compete with the straightforward off-pump coronary artery bypass sternotomy approach, which is today favored by many surgeons.

\section{Risk Factors for Technical Problems}

No single demographic risk factor was associated with the occurrence of technical difficulties, which was most likely influenced by the preselection of coronary patients with only a few comorbidities.

\section{Port-hole Problems}

There were no immediate problems with port positioning, but port bleeding after a smooth intraoperative course occurred in 3 patients of our series. One technical modification that we introduced after these events was to rigorously inspect the port holes with the camera from inside after port removal and to pack the port holes with collagen sponges before closure.

\section{LITA Damage}

LITA damage necessitating conversion or revision was observed in 3 cases of our series. Rigorous intraoperative quality control by means of on-table angiography helped to detect one significant intramural hematoma. LITA damage has been described in other TECAB series but also in series in which conventional thoracoscopic instrumentation was used to endoscopically harvest the vessel. ${ }^{7-9}$

\section{Epimyocardial Lesions}

In 3 cases of our series, a laceration of the right ventricular outflow tract had to be repaired with endoscopic sutures. These lesions all occurred when an instrument was inserted without direct videoscopic view. Special attention therefore needs to be paid that instruments are brought into the thoracic cavity by the patient-side surgeon only under clear direct vision. Dogan and coworkers ${ }^{4}$ have previously underlined the critical role of the patient-side surgeon for various aspects of the procedure. As a preemptive strategy, we try to avoid personnel changes in the TECAB team. In the case that required conversion, forced inflation of the right lung after separation from cardiopulmonary bypass under single-lung ventilation probably played a role in the occurrence of a laceration.

\section{Anastomotic Bleeding}

One special feature of telemanipulation-enhanced endoscopic CABG is that the anastomosis is sutured by the console surgeon in a running fashion without countertraction by an assistant. We regard this fact as the main reason why 4 cases of bleeding occurred in our learning series. Similar bleeding problems have been described by Dogan and coworkers. ${ }^{4}$ The console surgeon during the learning phase has to adapt to the degree of suture tension that is 
necessary for an avoidance of loose slings, which might cause anastomotic leakage. Two cases of anastomotic bleeding were diagnosed by means of intraoperative angiography and visualized by means of extravasation of contrast medium. Two further cases were diagnosed by means of direct inspection during a revision procedure for bleeding. In all these cases, final inspections with videoendoscopy had shown a blood-tight anastomosis. There might be factors that could lead to loosening of the single surgeon-performed suture during the immediate postoperative period. We changed our protocol in such a way that preventive repair stitches are placed in any case of doubtful oozing after release of the LITA bulldog and that fibrin glue is generously applied onto the anastomosis after heparin reversal. No case of bleeding has occurred after introduction of these measures.

\section{Target Vessel Occlusion}

We experienced 2 cases of target vessel occlusion close to the heel of the anastomosis. Both cases occurred in patients with significant local vessel wall pathology, and both were detected on intraoperative angiography. One possible explanation could be the current suture technique, in which the heel stitches are placed on the target vessel in an outside-in fashion. Local plaque mobilization might have been a consequence of this technique, leading to local vessel obstruction by the plaque. A consequence of the target vessel occlusions was increased concentration at placement of the heel stitches under inspection of the whole surgical team and endoscopic probing of all anastomoses. Narrowing of the anastomosis at the heel has not occurred throughout the second half of the series.

\section{Remote Access Perfusion Problems}

In our series one single severity level 5 technical difficulty (external iliac artery injury caused by an additional perfusion cannula in the groin contralateral to the RAP cannula) was encountered with remote access perfusion. This event was unrelated to the specific remote access perfusion cannula, which was used in all our cases. ${ }^{10}$ Aortic dissection, which was described in early arrested heart TECAB series by other groups, did not occur. ${ }^{4} \mathrm{We}$ attribute this in part to the fact that preoperative computed tomographic scans were performed in every patient for detection of significant aortic or iliacal atherosclerotic lesions and for determination of an adequate ascending aortic diameter for balloon placement. Nevertheless, failure of correct positioning of the occlusion balloon necessitated conversion to sternotomy in 2 cases. It might be of note that the majority of remote access perfusion problems in our series were level 1 in severity, leading only to a delay in operative time.

\section{Overall Outcome}

According to our experience, technical problems in AHTECAB increased the postoperative ventilation time. Single-lung ventilation and prolonged cardiopulmonary bypass time in combination with a surgically complicating event are probable explanations for this fact. Hospital stay was also increased by only 1 day if technical difficulties occurred. It is satisfying that despite significant challenges, no mortality occurred. Our $0 \%$ mortality is also in line with low mortality rates reported by other TECAB groups during their learning curve. ${ }^{2-4}$ The overall freedom from angina and graft potency at 3 years were not affected by surgeonrelated technical difficulties. There was no target vessel reintervention on the robotically sutured LITA grafts in the whole study group.

\section{Limitations of the Study}

Our study is limited by the fact that a small and selected group of patients has been chosen for performance of TECAB. Results will have to be confirmed with much larger patient numbers in multicenter registries and expansion of AHTECAB into multivessel disease. Larger patient series will also show whether the too-high rate of larger incisions in about one third of the patients can be reduced.

\section{Limitations of the AHTECAB Procedure}

The current rate of LITA injuries in 1 of 10 patients, anastomotic problems in 1 of 5 patients, and remote access perfusion difficulties in 1 of 4 patients also requires significant improvement. It is clear that with off-pump coronary artery bypass sternotomy or minimally invasive direct coronary artery bypass grafting (MIDCAB) techniques, cardiopulmonary bypass could be avoided completely and that compared with a sternotomy, on-pump procedure cardiopulmonary bypass time and aortic cross-clamp time, with their known side effects, are significantly increased.

\section{Conclusion}

We conclude that during an implementation phase of telemanipulation-enhanced TECAB carried out on the arrested heart with remote access perfusion, technical challenges might be frequently encountered. With proper monitoring of these events, rigorous intraoperative quality control, close postoperative observation, and immediate surgical reaction, however, the sequelae for the patients are acceptable. The overall intermediate-term postoperative outcomes (freedom from angina and graft patency) are not compromised by the occurrence of these technical challenges. Intense technologic and procedure-related devel- 
opment will be necessary to reduce the rate of undesirable events.

\section{Addendum}

Since acceptance of the manuscript, 19 more AHTECAB LITA to LAD procedures were carried out at Innsbruck Medical University. Technical difficulties occured in 6 out of these operations (32\%) with a mean severity level of $0.4 \pm 0.6$. Intraoperative conversion was necessary in only 1 patient $(5 \%)$ and there were no postoperative revision procedures.

\section{References}

1. Loulmet D, Carpentier A, d'Attellis N, et al. Endoscopic coronary artery bypass grafting with the aid of robotic assisted instruments. J Thorac Cardiovasc Surg. 1999;118:4-10.

2. Kappert U, Schneider J, Cichon R, et al. Development of robotic enhanced endoscopic surgery fort the treatment of coronary artery disease. Circulation. 2001;104(suppl I):I102-7.
3. Falk V, Diegeler A, Walther T, et al. Total endoscopic computer enhanced coronary artery bypass grafting. Eur J Cardiothorac Surg. 2000;17:38-45.

4. Dogan S, Aybek T, Andressen E, et al. Totally endoscopic coronary bypass grafting on cardiopulmonary bypass with robotically enhanced telemanipulation: report of forty-five cases. J Thorac Cardiovasc Surg. 2002;123:1125-31.

5. Bonatti J, Schachner T, Bernecker O, et al. Robotic totally endoscopic coronary artery bypass: program development and learning curve issues. J Thorac Cardiovasc Surg. 2004;127:504-10.

6. Ott H, Bonatti J, Müller L, Chevtchik O, Riha M, Laufer G. Robotically enhanced cardiac surgery. Eur Surg. 2002;34:183-9.

7. Nataf P, Lima L, Regan M, et al. Thoracoscopic internal mammary artery harvesting: technical considerations. Ann Thorac Surg. 1997; 63(suppl):S104-6.

8. Duhaylongsod FG, Mayfield WR, Wolf RK. Thoracoscopic harvest of the internal thoracic artery: a multicenter experience in 218 cases. Ann Thorac Surg. 1998;66:1012-7.

9. Nataf P, Al-Attar N, Ramadan R, et al. Thoracoscopic IMA takedown. J Card Surg. 2000;15:2778-82.

10. Schachner T, Bonaros N, Laufer G, Bonatti J. The ESTECH remote access perfusion cannula in minimally invasive cardiac surgery. Heart Surg Forum. 2004;7:503-6. 